\title{
UMA ANÁLISE DA INFLUÊNCIA DE RECURSOS ELETRÔNICOS E EFICÁCIA DO EMPREGO DE PLATAFORMAS VIRTUAIS DURANTE O REGIME DE EXERCÍCIOS DOMICILIARES ESPECIAIS
}

Andressa Wickert Kreutz ${ }^{1}$ - andressakreutz@gmail.com

Davi Sehnem Castro ${ }^{1}$ - davisehnem99@gmail.com

Diego Henrique Nyland ${ }^{1}$ - nyland.diego@gmail.com

Emmanuel Adamski de Moura ${ }^{1}$ - emmanomoura@gmail.com

Eugênio Piveta Pozzobon ${ }^{1}$ - eugeniopp00@gmail.com

Lucas Biselo Piton' - lucasbpiton@gmail.com

Max Anacleto Vasconcelos ${ }^{1}$ - vasconcelosanacletomax@gmail.com

Natanael Rodrigues Gomes ${ }^{2}$ - natanael.rgomes@gmail.com

Viviane Luíse Silva de Lima ${ }^{\mathbf{1}}$ - vivianelsdelima@gmail.com

${ }^{1}$ Bolsista do Programa de Educação Tutorial (PET) Engenharia Elétrica

${ }^{2}$ Tutor do Programa Educação Tutorial (PET) Engenharia Elétrica

Universidade Federal de Santa Maria

Av. Roraima, 1000-7 - Camobi

97105-900 - Santa Maria - Rio Grande do Sul

Resumo: Devido a atual situação envolvendo a pandemia de COVID-19 e as medidas de distanciamento social adotadas pela Universidade Federal de Santa Maria (UFSM) para conter o avanço do vírus, os alunos ficaram momentaneamente impedidos de assistir aulas presenciais. Como solução, um plano para o uso de atividades acadêmicas a distância foi aprovado, o REDE (Regime de Exercícios Domiciliares Especiais), que permite a utilização de plataformas online para dar continuidade ao semestre letivo. Estas, porém, são ferramentas não comumente utilizadas no ensino, o que causa estranheza e dificuldade de adaptação por parte dos docentes e discentes. Desta forma, o Programa de Educação Tutorial Engenharia Elétrica (PET-EE) elaborou um questionário visando coletar opiniões e relatos sobre as aulas ministradas, bem como sugestões para a melhora das mesmas, tanto por parte dos alunos quanto dos professores. Neste, procurou-se averiguar qual é a situação dos alunos e professores do curso de Engenharia Elétrica, tratando aspectos técnicos de internet e de plataformas usadas para o aprendizado, identificando quais destas são consideradas mais eficazes.

Palavras-chave: COVID-19. Ensino a Distância. Home-Office. Recursos eletrônicos. Plataformas virtuais de ensino.

\section{INTRODUÇÃO}

No atual contexto de isolamento social devido a questões de saúde pública, a Universidade Federal de Santa Maria (UFSM) faz parte, de acordo com a Folha de São Paulo, das 25 universidades federais que adotaram o ensino à distância para dar continuidade às aulas. Para isso, criou o REDE, uma forma remota de continuar as aulas. 
A implementação do REDE não é obrigatória, ficando a critério dos professores optarem por aderir a este regime ou não. Da mesma forma, os alunos podem avaliar se conseguem executar as atividades do REDE, sendo disponibilizado tempo para recuperação das mesmas de maneira presencial, posteriormente. Todavia, após alguns dias do REDE, foi questionada a real efetividade desse método, que até então nunca tinha sido praticado pela universidade, desenvolvendo-se meios para avaliar o mesmo.

\section{JUSTIFICATIVA}

O REDE é uma alternativa para a continuidade dos estudos, de maneira a se permitir o contato entre alunos e professores, característica importante para a construção de conhecimento. Porém, tal situação se desenvolveu de maneira repentina, sem preparação e organização prévia. Desse modo, há a necessidade de adaptações a este novo modelo de ensino tanto por professores como por alunos, de maneira que o aprendizado seja efetivo.

Nessa conjuntura, o PET-EE buscou recolher opiniões de docentes e de discentes, a fim de avaliar qual metodologia e quais mecanismos empregados no ensino à distância, na visão destes, podem auxiliar em uma melhor assimilação do conteúdo ministrado no REDE. Sendo assim, pretendeu-se analisar a influência de recursos digitais e dados técnicos, tais como acesso e qualidade de internet, além da eficácia do emprego de ferramentas como vídeos, videoconferência, arquivos de áudio e de texto, entre outros, neste modelo de ensino.

Em vista disso, intenta-se auxiliar alunos e professores nesse processo de adaptação, construindo um meio de comunicação entre ambas as partes e possibilitando troca de experiências, de modo que se possa percorrer este período da melhor maneira possível e minimizar os danos causados ao aprendizado. Para fins de análise, foi proposto um questionário aos professores e alunos do curso de Engenharia Elétrica da UFSM, o qual ficou disponível por um período de duas semanas e obteve 76 respostas, dentre as quais 8 foram de docentes e 68 de discentes.

\section{ANÁLISE DOS RESULTADOS DO QUESTIONÁRIO}

\subsection{Visão dos professores}

Dentre os professores que responderam o questionário, $87.5 \%$ afirmaram ter adotado as atividades propostas pelo REDE, enquanto os outros $12.5 \%$ dizem não ter adotado e que não pretendem aderir tal metodologia. Estes números mostram uma ampla adoção por parte dos docentes em dar prosseguimento ao semestre mesmo em período de quarentena.

Ainda, 87.5\% dos docentes que estão realizando aulas através do REDE, normalmente ministram aulas de caráter teórico e prático, entretanto apenas 37.5\% destes relatam estar suprindo a carga horária prática do conteúdo, optando por esperar pela volta das aulas presenciais para realizá-las em laboratório. Aqueles que estão dando prosseguimento às atividades práticas, o fazem através de softwares de simulação, como MATLAB, PSIM, entre outros, que podem ser utilizados pelos alunos em seus computadores pessoais.

Dentre os métodos aplicáveis através do REDE, a videochamada é um método que supre a necessidade do debate e do diálogo presente e contínuo para exposição de aulas em formato streaming. Sabendo disso, foram questionadas as plataformas usadas para a realização de transmissões ao vivo, por meio da pergunta da Figura 1. 
Figura 1 - Plataformas utilizados pelos professores.

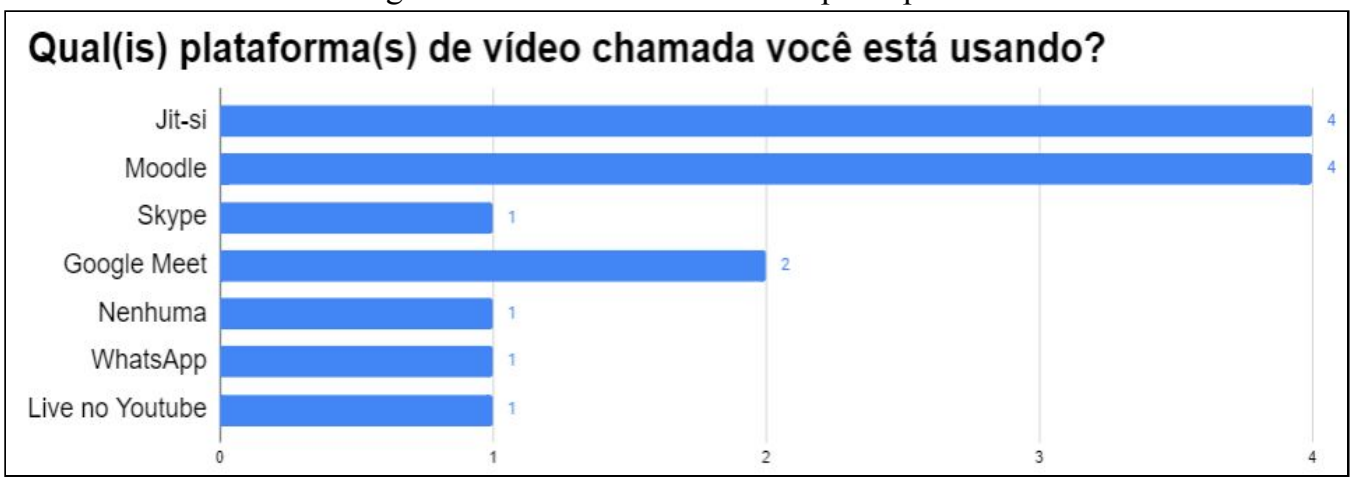

Fonte: Autores

A partir do gráfico da Figura 1, nota-se que entre as plataformas escolhidas pelos professores, o Moodle e o Jit-si se destacam. Ademais, verificou-se que alguns professores tentaram usar mais de uma plataforma, visto que 8 professores responderam o formulário, e um deles não aderiu ao REDE. Isso é um indício importante de que alguma plataforma não atendeu às necessidades dos professores e precisou ser substituída.

Além de realizar aulas por videoconferência, todos os docentes entrevistados afirmaram gravar e disponibilizar estas aulas posteriormente em outras plataformas, como o Moodle, Google Drive ou Youtube, já que uma parcela dos alunos não possuem qualidade de internet suficiente para acompanhar as aulas ou possuem afazeres em horários conflitantes com os horários das aulas. Isso é perceptível pelo comentário de um dos docentes que respondeu o formulário, "Minha experiência está sendo positiva, comecei tendo bastante participação dos alunos. No entanto, muitos têm reclamado da internet e estão assistindo às aulas que eu deixo gravadas no YouTube."

Pela Figura 2, é possível perceber que a tática atual dos professores é replicar as aulas presenciais em videoconferência, com metodologia comumente usada presencialmente.

Figura 2 - Metodologias adotadas pelos docentes.

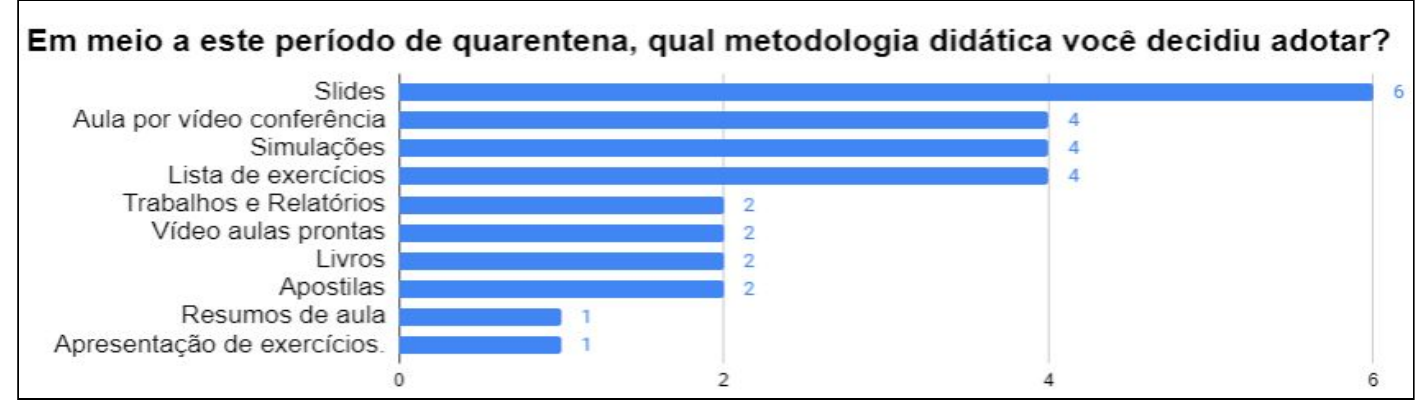

Fonte: Autores

Os professores mencionam que sentem mais engajamento do que presencialmente. Isso pode demonstrar que a falta de outras atividades da maior parte dos alunos colabora para um bom desempenho nas atividades propostas pelo REDE, tendo em vista fatores psicológicos associado ao cumprimento de afazeres. Outrossim, segundo os relatos dos professores, a maior dificuldade é obter um retorno dos alunos e ter ideia se o andamento das aulas por meio do REDE está indo bem ou não. Para que os professores possam desempenhar melhor sua 
função, é necessário que haja retorno e feedback por parte dos alunos, é uma via de mão dupla. Um dos comentários resume bem o todo:

"No geral, os alunos estão enviando as tarefas propostas, acessando as aulas gravadas, mas o nível de interação (questionamentos, dúvidas, etc.) tem sido abaixo do esperado. [...] Mas mesmo nas aulas presenciais, em muitas turmas percebo este baixo nível de interação, que na minha opinião, não contribui para $\mathrm{o}$ processo de ensino-aprendizagem. De modo geral, gostaria que os alunos fossem mais participativos." (ANÔNIMO, 2020).

\subsection{Uma Visão Discente}

Dos 68 alunos entrevistados, um percentual de 86,8\% está matriculado neste semestre em 6 disciplinas ou mais. Entretanto, apenas $23,6 \%$ dos alunos possuem 6 ou mais disciplinas que estão empregando o REDE. Também, 70,6\% dos estudantes apresentam dificuldade para se adaptar aos métodos de ensino empregados no REDE. Tais números indicam baixa adesão dos docentes às ferramentas que auxiliam em atividades a distância e problemas de adaptação às mesmas por parte dos discentes.

Além disso, um percentual de $80,9 \%$ dos estudantes afirmou que dentre as disciplinas que seguem sendo ministradas através do REDE, ao menos uma possui determinada carga horária prevista para atividades práticas. Porém, somente $7,9 \%$ destes alunos confirmaram que todos os seus professores de disciplinas com parte prática estão desenvolvendo atividades vinculadas a este quesito. Já para $85,8 \%$ dos alunos, somente alguns ou nenhum dos docentes estão cumprindo carga horária prática das disciplinas. Dessa forma, verifica-se a carência de ferramentas para realização de muitas atividades laboratoriais a distância, visto que os alunos não possuem componentes e instrumentos técnicos em suas casas para execução de projetos, por exemplo. Constata-se, assim, a necessidade de buscar outros meios que permitam alguma consolidação do conhecimento prático, tais como simulações em softwares, deixando-se a execução em si para o retorno das aulas presenciais.

Nessa situação, os docentes das disciplinas estão buscando maneiras de continuar ministrando suas aulas, visando minimizar os danos ao aprendizado dos alunos, por meio do uso de diversas plataformas. Assim, os discentes do curso de engenharia elétrica da UFSM foram questionados sobre quais plataformas os professores estão usando, podendo-se assinalar mais de uma opção. A Figura 3 apresenta o gráfico das respostas dos alunos.

Figura 3 - Ferramentas utilizadas pelos professores no REDE sob vista dos alunos.

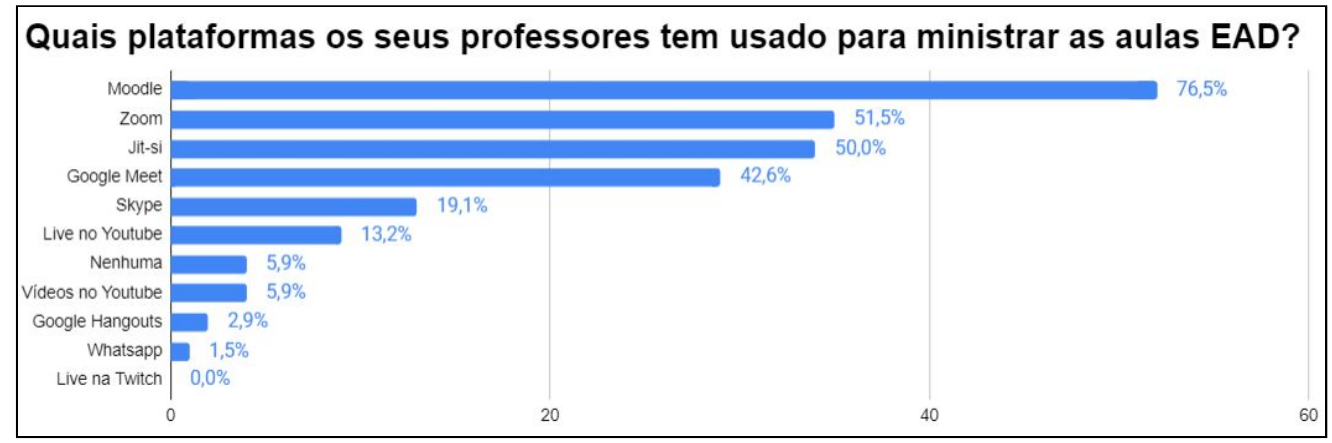

Fonte: Autores 
Analisando as respostas, pode-se apontar que o Zoom, Jit-si e o Google Meet são as ferramentas que se destacam no ramo de streaming, além disso, o Moodle se destaca como principal plataforma para disponibilizar conteúdos como aulas gravadas, livros, resumos, slides, trabalhos e listas de exercício. Na Figura 4, é observada a opinião dos estudantes a respeito de qual plataforma de videoconferência é considerada melhor pelos mesmos, podendo-se marcar mais de uma opção.

Figura 4 - Opinião dos alunos sobre melhor plataforma de videoconferência

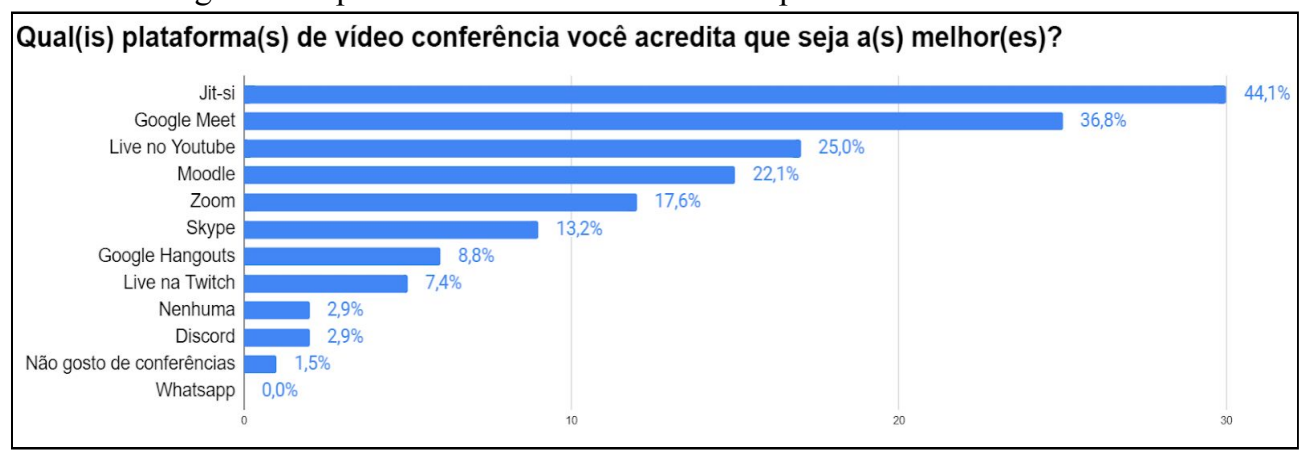

Fonte: Autores

Nota-se que Jit-si, Google Meet, live no Youtube e Moodle foram as plataformas mais escolhidas. Com base nessas informações, pode-se perceber que, em geral, as ferramentas mais utilizadas pelos professores também são as que os alunos acreditam ser as melhores.

A Figura 5 expressa a opinião dos alunos sobre quais métodos estão sendo mais eficientes neste momento, sendo possível assinalar mais de uma opção. Observa-se que os itens elencados pelos estudantes como mais apropriados para atividades em REDE são lista de exercícios, aulas gravadas do docente, slides e a realização de aulas ao vivo por videoconferência.

Figura 5 - Opinião dos alunos sobre métodos mais eficientes de ensino adotados no REDE.

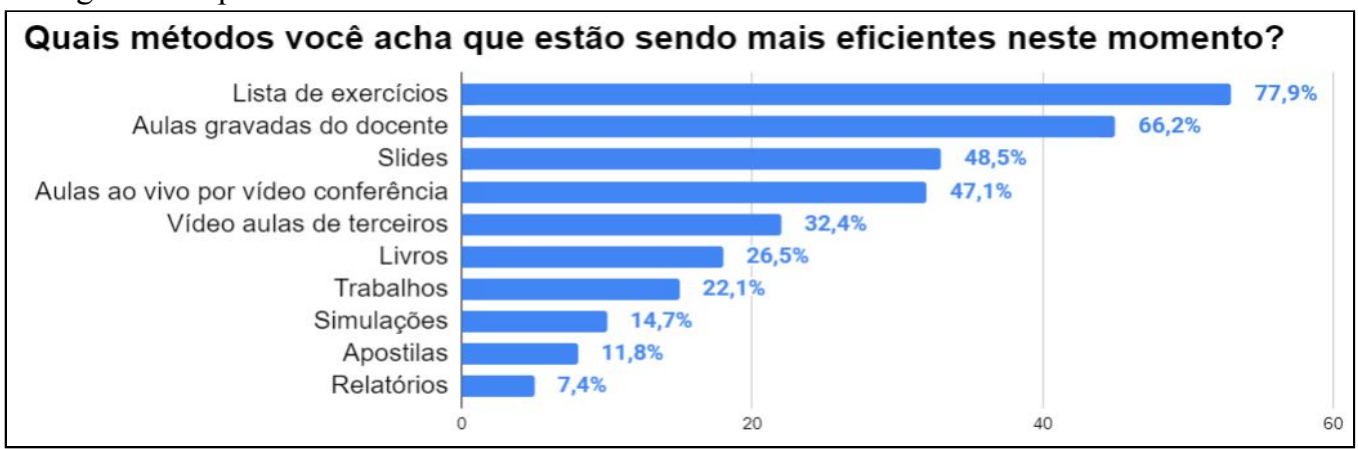

Fonte: Autores

Analisando as sugestões descritivas dos alunos dadas aos professores a fim de melhorar o REDE, percebe-se que boa parte destes consideram importante as aulas por videoconferência, principalmente por estabelecer um horário de compromisso com a disciplina e promover uma interação professor-aluno. No entanto, os estudantes sugerem que essas aulas sejam gravadas e disponibilizadas através de alguma ferramenta, como por exemplo, o Youtube, que possibilita a alteração de velocidade do vídeo, além de estarem disponíveis para acesso sempre que necessário. Isso por conta da instabilidade da internet no momento do uso da 
ferramenta de videoconferência, pelo ruído do ambiente em que o aluno se encontra que poderá prejudicar o entendimento da aula ou até mesmo por causa da dificuldade de adaptação a esse período.

Além das vídeo aulas, os estudantes solicitam que sejam fornecidas listas de exercícios e pequenos trabalhos com o objetivo de consolidar o conteúdo ministrado. Dessa forma, as videoconferências ao vivo seriam também um espaço para sanar dúvidas sobre o material teórico disponibilizado. Já em relação às atividades relacionadas a carga horária prática, foi sugerido que essas fossem realizadas através de softwares de simulação e que fossem elaborados relatórios por parte dos alunos sobre tais simulações. Além disso, obteve-se uma resposta de um aluno que já possui experiências passadas com ensino a distância e que confirma os comentários e as sugestões analisadas.

"Já tive experiência de estudar 1 semestre em um curso totalmente EAD em outra universidade. Com base nessa minha curta experiência, acredito que o melhor método seja: aulas gravadas disponíveis para os alunos (ou aulas ao vivo, mas que sejam gravadas e disponibilizadas depois para os alunos) + conteúdo escrito disponibilizado também (seja na forma de slides, resumos, indicação de capítulos de livros ou mesmo link de vídeos) + entrega semanal de exercícios ou trabalhos (pois isso força os alunos procrastinadores a manterem o ritmo junto com a turma, evitando deixar muitos alunos para trás) + encontro semanal ao vivo para tirar dúvidas (antes do prazo de entrega dos trabalhos/exercícios)" (ANÔNIMO, 2020).

Também, foi proposta a realização de webinars ou desenvolvimento de tutoriais, como forma de troca de experiências entre os professores sobre métodos possíveis de serem adotados no REDE e que estão sendo eficientes para o aprendizado.

\subsection{Visão geral}

A partir da pesquisa realizada, foi possível avaliar as condições do acesso a internet dos alunos participantes. Com os resultados obtidos, pode-se perceber que parte considerável dos alunos possuem acesso amplo e diário a uma conexão com a rede. No entanto, é importante salientar que uma parcela considerável $(6,6 \%)$ não possui acesso diário à internet. Este valor pode ser ainda mais significativo, visto que a pesquisa foi realizada de forma online, assim, apenas os alunos que possuem conexão puderam responder.

Figura 6 - Tempo de acesso a internet diariamente.

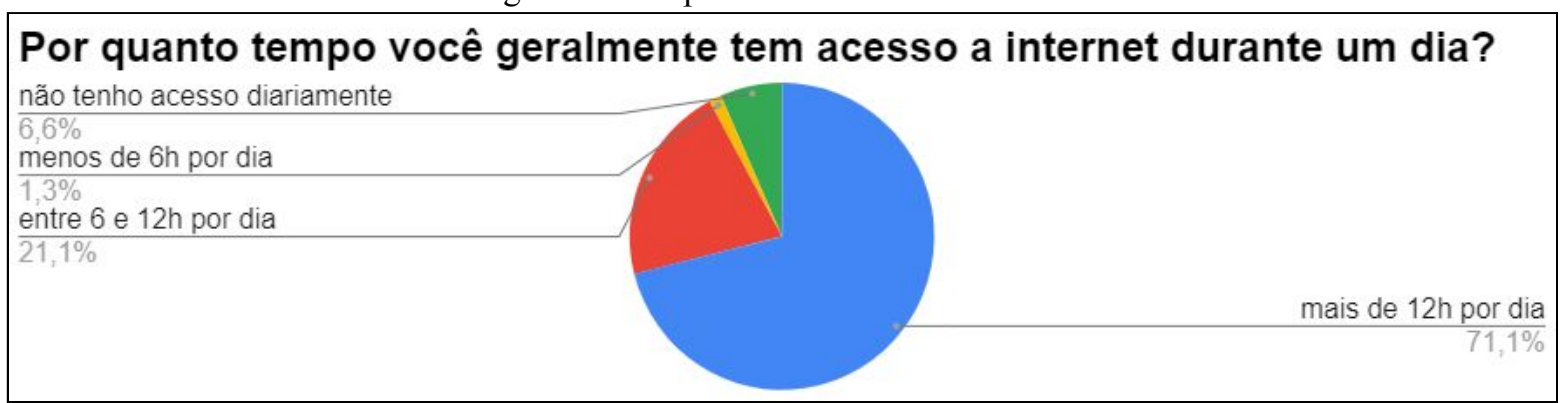

Fonte: Autores

Outro fator que deve ser levado em conta é que possuir uma conexão diária com a internet não significa uma conexão de qualidade. Desta forma, muitos alunos podem ser 
prejudicados pela falta de estabilidade e confiabilidade da rede, que pode falhar durante aulas online feitas no formato de streaming (transmissão ao vivo). Para quantificar a influência destes fatores no rendimento acadêmico durante este período de isolamento social, foi realizada a pergunta da Figura 7.

Figura 7 - Opinião dos acadêmicos sobre suas velocidade e estabilidade da internet.

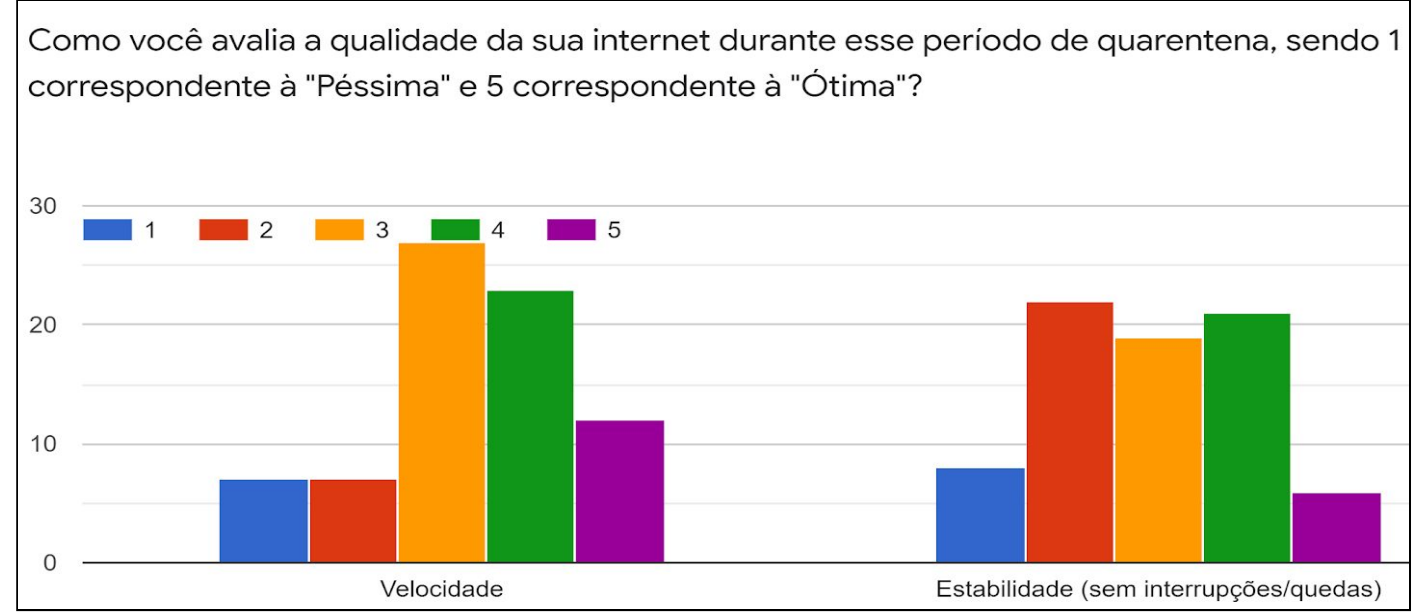

Fonte: Autores

Assim, verificou-se que grande parte dos alunos possuem maiores problemas na estabilidade da conexão do que na sua velocidade, conforme relatos dos mesmos. Ou seja, o acesso a internet pode ocorrer de forma veloz, permitindo a visualização de vídeo-chamadas e transmissões ao vivo, no entanto, falta confiabilidade ao sistema. Desta maneira, as faltas na conexão podem ocorrer justamente no momento das aulas, o que prejudica bastante o aluno. Esta falta de estabilidade também pode acarretar em atrasos na entrega de tarefas.

\section{ANÁLISE TÉCNICA DOS RECURSOS DE HARDWARE E LARGURA DE BANDA SOLICITADOS NO ENSINO A DISTÂNCIA}

Buscando compreender melhor a demanda dos participantes da pesquisa em relação a largura de banda, foi feito um levantamento de quais são as recomendações para o uso de plataformas que suportam videoconferências, considerando as plataformas apontadas pelos discentes, com base nas respostas exibidas nas Figuras 3 e 4 . O critério na escolha das conferências por vídeo como parâmetro para a avaliação da largura de banda foi determinado, inicialmente, verificando quais métodos estavam sendo empregados pelos docentes, por meio dos dados mostrados na Figura 2, e posteriormente, selecionando qual dos métodos solicita maior largura de banda. Fundamentando-se na noção de que a comunicação via vídeo solicita uma maior taxa de transmissão de dados, em termos de download e upload, do que outras formas de comunicação usadas pelos docentes, as videoconferências foram destacadas para medir a largura de banda exigida para que seja viável participar de aulas ou demais atividades.

Definiu-se como parâmetro, minimamente 7 usuários simultâneos e preferencialmente 10 usuários simultâneos em videoconferência, com exceção do WhatsApp que não informa o número de usuários para os dados disponibilizados. Outra observação é que não foi encontrado para o Skype qual a resolução que estava sendo usada como referência para os 
"Os desafios para formar hoje o engenheiro do amanhã"

dados informados, High Definition (HD) ou Standard Definition (SD), sendo escolhida a menos favorável. O resultado obtido com o levantamento é exibido no Quadro 1.

Quadro 1: Requisitos mínimos para diferentes plataformas em High Definition e Slow Definition

\begin{tabular}{|l|c|c|c|c|}
\hline Plataforma & Upload (HD) & Download (HD) & Upload (SD) & Download (SD) \\
\hline Google Hangouts & $4 \mathrm{Mbps}$ & $2,6 \mathrm{Mbps}$ & - & - \\
\hline Google Meet & $3 \mathrm{Mbps}$ & $4 \mathrm{Mbps}$ & $1 \mathrm{Mbps}$ & $2 \mathrm{Mbps}$ \\
\hline Jit-si & - & - & $3,4 \mathrm{Mbps}$ & $6,1 \mathrm{Mbps}$ \\
\hline Moodle & - & - & $0,5 \mathrm{Mbps}$ & $1 \mathrm{Mbps}$ \\
\hline Live na Twitch & - & - & $3 \mathrm{Mbps}$ & $1,5 \mathrm{Mbps}$ \\
\hline Live no Youtube & $3 \mathrm{Mbps}$ & $7 \mathrm{Mbps}$ & $1,5 \mathrm{Mbps}$ & $3 \mathrm{Mbps}$ \\
\hline Skype & - & - & $128 \mathrm{kbps}$ & $4 \mathrm{Mbps}$ \\
\hline $\begin{array}{l}\text { Vídeos no } \\
\text { YouTube }\end{array}$ & - & $7 \mathrm{Mbps}$ & - & $3 \mathrm{Mbps}$ \\
\hline Whatsapp & - & - & $2,9 \mathrm{Mbps}$ & $2,9 \mathrm{Mbps}$ \\
\hline Zoom & $2.5 \mathrm{Mbps}$ & $2.5 \mathrm{Mbps}$ & $800 \mathrm{kbps}$ & $1 \mathrm{Mbps}$ \\
\hline
\end{tabular}

Fonte: Autores

Tendo em vista que parte do conteúdo do curso de Engenharia Elétrica é composto de atividades práticas, as simulações implementadas em ambiente domiciliar surgem como uma alternativa que pode auxiliar com a componente prática das disciplinas. Esta abordagem foi utilizada conforme o relato de alguns professores no questionário.

Sendo assim, foi realizado um levantamento visando inferir quais são os recursos necessários com relação aos computadores do ponto de vista de hardware. Para um conjunto de softwares que usualmente são utilizados ao longo do curso, foram elencadas as recomendações de hardware de acordo com seus desenvolvedores. Os dados obtidos se encontram no Quadro 2.

O Moodle é o ambiente virtual institucional da UFSM, ferramenta cuja demanda cresceu no período de isolamento social, conforme publicado na página do Núcleo de Tecnologia Educacional (NTE). Para avaliar a capacidade da webconferência embutida no Moodle, contatou-se o NTE, que informou que o servidor BigBlueButton (BBB) da UFSM tem capacidade de atender até 1200 usuários totais simultâneos, sendo relatada a degradação de áudio acima de 960 usuários totais simultâneos, ou com mais de 100 usuários em uma mesma conferência. Também foi informado que além dos requisitos de largura de banda, informados no quadro 1, é recomendável que o dispositivo utilizado no acesso, seja computador ou smartphone, possua no mínimo $2 \mathrm{~GB}$ de RAM. Vale a ressalva feita, de que os valores apresentados estão sujeitos à variação de acordo com a forma de uso dos acessantes (se está sendo transmitida imagem de câmera e com qual resolução).

Quadro 2: Requisitos mínimos para diferentes softwares

\begin{tabular}{|r|c|c|c|c|c|c|}
\hline Software & RAM & HD/SSD & Processador & Placa de vídeo & Versão do S.O. & Arquitetura \\
\hline ANACONDA & - & $5 \mathrm{~GB}$ & - & - & Windows 8/ & 64 bits \\
\hline
\end{tabular}


"Os desafios para formar hoje o engenheiro do amanhã"

\begin{tabular}{|r|c|c|c|c|c|c|}
\hline & & & & & MacOS 10/ Linux & \\
\hline AutoCAD & $\begin{array}{c}8 \mathrm{~GB} / 4 \mathrm{~GB} \\
(\mathrm{~W} / \mathrm{Mac})\end{array}$ & $12 \mathrm{~GB}$ & $2,5 \mathrm{GHz}$ & $\begin{array}{c}1 \mathrm{~GB} \text { GPU e suporte } \\
\text { para DirectX 11 }\end{array}$ & $\begin{array}{c}\text { Windows 8.1/ } \\
\text { MacOS 10.13 }\end{array}$ & 64 bits \\
\hline CodeBlocks & $512 \mathrm{MB}$ & - & - & - & Windows XP & - \\
\hline DEVC++ & $32 \mathrm{MB}$ & - & - & - & Windows95 & - \\
\hline KICAD & $1 \mathrm{~GB}$ & $10 \mathrm{~GB}$ & & $\begin{array}{c}\text { Suporte para OpenGL } \\
2.1\end{array}$ & $\begin{array}{c}\text { Windows 7/ } \\
\text { MacOS 10/ Ubuntu }\end{array}$ & 64 bits/32bits \\
\hline LaTeX Editor & $4 \mathrm{MB}$ & $4 \mathrm{MB}$ & $333 \mathrm{MHz}$ & - & Windows 2000 & - \\
\hline LT Spice & $1 \mathrm{~GB}$ & $10 \mathrm{~GB}$ & - & - & Windows 98/ Linux & - \\
\hline MATLAB & $4 \mathrm{~GB}$ & $10,9 \mathrm{~GB}$ & Intel/ AMD & - & Windows 10 & $64 \mathrm{bits}$ \\
\hline PROTEUS & $3 \mathrm{~GB}$ & - & $2 \mathrm{GHz}$ & $\begin{array}{c}\text { Suporte para OpenGL } \\
2.0 / \text { Direct 3D }\end{array}$ & Windows 10 & - \\
\hline PSIM & $2 \mathrm{~GB}$ & $20 \mathrm{~GB}$ & $>4000^{1}$ & - & Windows 7 & $64 \mathrm{bits} / 32 \mathrm{bits}$ \\
\hline WEG Ladder & $512 \mathrm{MB}$ & - & - & - & Windows XP SP3 & - \\
\hline
\end{tabular}

Fonte: Autores

\section{CONSIDERAÇÕES FINAIS}

A partir da pesquisa realizada, foi possível compilar relatos de docentes e discentes da UFSM. Esta coleta de dados teve como objetivo construir uma análise a respeito das metodologias de aula e principais plataformas online, a fim de manter o processo de ensino com a melhor qualidade possível diante do período de isolamento social ocasionado pelo COVID-19. Com os dados obtidos, averiguou-se que o acesso a uma conexão com a internet estável e rápida ainda não é uma realidade para os diversos alunos da instituição, o que vêm ocasionando problemas no acompanhamento de aulas por videoconferência e na realização de atividades online dentro do prazo estabelecido pelo professor.

Desta forma, foram constatadas diversas dificuldades de conexão, principalmente por parte dos alunos, visto que o corpo discente da instituição é bastante amplo, apresentando realidades sociais e econômicas muito distintas. Assim, foi possível obter relatos de alunos que possuem dificuldades para acompanhar transmissões ao vivo ou realizar tarefas online. Além disso, a dificuldade no aprendizado durante o período de isolamento social também deriva da falta de padronização e planejamento para as atividades a distância, visto que o regime especial precisou ser implantado com urgência.

A falta de padronização faz com que cada docente utilize a plataforma de sua preferência para realizar suas aulas, o que causa dificuldades de escolha da plataforma por parte do professor, visto que este pode desconhecer estes recursos digitais. Algumas plataformas também exigem mais recursos de internet que outras, o que pode resultar em problemas para o aluno.

Nos resultados da pesquisa, foi possível notar a importância das videoconferências para auxiliar os estudantes a sanar dúvidas, além de manter um horário fixo para o estudo, durante a semana. Porém, este método de ensino a distância necessita de uma conexão estável e de qualidade. Para tanto, uma das possíveis soluções seria disponibilizar o material fornecido durante as aulas, em formato de apresentação de slides, arquivos com os roteiros das aulas, ou até mesmo a bibliografia utilizada. Outra solução seria disponibilizar gravações das aulas,

\footnotetext{
${ }^{1}$ Ranking CPU Benchmark. Disponível em: <https://www.cpubenchmark.net/cpu_list.php>. Acesso
} em: 31 maio 2020 
através de plataformas como o YouTube. Assim, os alunos que enfrentarem faltas na conexão no horário estabelecido para aula terão a possibilidade de retomar o conteúdo mais tarde, quando a conexão voltar a estabilizar. Para auxiliar na fixação dos conteúdos, também é interessante manter uma rotina de exercícios e pequenos trabalhos.

\title{
REFERÊNCIAS
}

COLUSSO, P.R. Ambiente Virtual Institucional MOODLE - UFSM - NTE. UFSM Universidade Federal de Santa Maria, 2020. Disponível em:

$<$ https://www.ufsm.br/orgaos-suplementares/nte/2020/04/27/ambiente-virtual-institucional-m oodle-ufsm/> Acesso em: 28 maio 2020.

FUJI, N. Jitsi Video Server and End User Bandwidth Rough Estimation. Google Docs, 2020. Disponível em:

$<$ https://docs.google.com/document/d/1pKOhjao-GjQTrlGVVMLjzqPmBH9kVDm4Iz_0Yc1 3HI/edit> Acesso em: 8 maio 2020.

PALHARES, Isabela. 60\% das universidades federais rejeitam ensino a distância durante quarentena. Folha de São Paulo, 2020. Disponível em:

$<$ https://www1.folha.uol.com.br/educacao/2020/03/60-universidades-federais-rejeitam-ensino -a-distancia-durante-quarentena.shtml> Acesso em: 26 maio 2020.

UFSM - NTE. Capacidade do Moodle. Mensagem recebida por <vasconcelosmax@hotmail.com> em 11 maio 2020.

\section{A ANALYSIS ON THE INFLUENCE OF ELECTRONIC RESOURCES AND EFFECTIVENESS OF EMPLOYMENT OF VIRTUAL PLATFORMS DURING THE REGIME DE EXERCÍCIOS DOMICILIARES ESPECIAIS}

\begin{abstract}
Due to the current situation involving the COVID-19 pandemic and the social distancing measures adopted by the Federal University of Santa Maria (UFSM) to contain the spread of the virus, students were momentarily prevented from attending classroom classes. As a solution, a plan for the use of remote academic activities was approved, called REDE (Regime de Exercícios Domiciliares Especiais), which allows the use of online platforms to continue the academic semester. These, however, are tools not commonly used in teaching, which causes strangeness and difficulty of adaptation on the part of teachers and students. Thus, the Electrical Engineering Tutorial Education Program (PET-EE) prepared a survey to collect opinions and reports on the classes taught, as well as suggestions for improving them, both on the part of students and teachers. The aim was to evaluate the situation of students and teachers of the Electrical Engineering course, addressing technical aspects of the internet and the platforms used for learning, identifying which of these are considered most effective.
\end{abstract}

Keywords: COVID-19. Home-Office. Distance learning. Electronic resources. Electronic resources. Virtual teaching platforms. 